\title{
Neighbourhood deprivation and obesity among 5656 pre-school children-findings from mandatory school enrollment examinations
}

\author{
Thuy Ha Nguyen ${ }^{1} \cdot$ Simon Götz $^{1} \cdot$ Katharina Kreffter $^{1} \cdot$ Stefanie Lisak-Wahl $^{2} \cdot$ Nico Dragano $^{1} \cdot$ Simone Weyers $^{1}$ (D)
}

Received: 10 November 2020 / Revised: 29 January 2021 / Accepted: 5 February 2021 / Published online: 11 February 2021

(C) The Author(s) 2021

\begin{abstract}
The risk of child obesity is strongly related to socioeconomic factors such as individual socioeconomic position (SEP) and neighbourhood deprivation. The present study analyses whether the relationship between neighbourhood deprivation and child obesity differs by child's individual SEP. Data from 5656 children (5-7 years) from the mandatory school enrollment examinations of the pre-school cohorts 2017/2018 in Düsseldorf were analysed. Obesity was determined by the age- and gender-specific body mass index (BMI); neighbourhood deprivation by using the socio-spatial degree of deprivation of the children's residential addresses; and individual SEP by the level of parental education. Using Poisson regression, we estimated prevalence ratios (PR with $95 \%$ confidence interval (CI)) of child obesity by neighbourhood deprivation and parental education. Interactions between neighbourhood deprivation and parental education were tested. The prevalence of child obesity increases with the degree of neighbourhood deprivation. Compared to children living in low deprivation neighbourhoods, the proportion of obese children was twice as high in high deprivation neighbourhoods ( $\mathrm{PR}=2.02 ; \mathrm{CI}=1.46-2.78)$. Likewise, children from families with medium and low education have twice the risk for obesity compared to children with high parental education ( $\mathrm{PR}=2.05$; $\mathrm{CI}=1.46-2.78$ ). The relationship between neighbourhood deprivation and child obesity was significantly moderated by parental education; it was stronger for higher parental education than for medium and low parental education $(p<.001)$.

Conclusion: Our findings suggest that children from deprived neighbourhoods and families with lower education have a higher risk for child obesity. The identification of particularly deprived neighbourhoods with structural interventions in combination with the strengthening of parental health literacy seems reasonable.
\end{abstract}

What is Known:

- Studies show that children from disadvantaged neighbourhoods are more frequently obese.

What is New:

- The relationship between neighbourhood deprivation and child obesity is significantly moderated by parental education. It is stronger for children with higher parental education than for children with medium and low parental education.

Keywords Paediatric obesity $\cdot$ Environmental health $\cdot$ Child health $\cdot$ Social inequalities $\cdot$ School entrance

Communicated by Gregorio Paolo Milani

Simone Weyers

Simone.Weyers@uni-duesseldorf.de

Thuy Ha Nguyen

Thuy.Ha.Nguyen@uni-duesseldorf.de

Simon Götz

Simon.Goetz@uni-duesseldorf.de

Katharina Kreffter

Katharina.Kreffter@uni-duesseldorf.de
Stefanie Lisak-Wahl

Lisak-Wahl@akademie-oegw.de

Nico Dragano

Dragano@med.uni-duesseldorf.de

1 Faculty of Medicine, University Hospital Duesseldorf, Centre for Health and Society, Institute of Medical Sociology, Moorenstrasse 5, 40225 Duesseldorf, Germany

2 Akademie für Öffentliches Gesundheitswesen, Düsseldorf, Germany 


\section{Introduction}

About every fifth child in Europe is overweight or obese [2]. Although the prevalence of overweight and obesity has plateaued [1], a considerable percentage of children is affected.

Overweight and obesity in childhood increase the risk for obesity in adulthood [42] and chronic diseases such as type 2 diabetes and coronary heart disease [34]. Mental health and emotional wellbeing can be compromised by obesity and the experience of stigma [30,31]. The World Health Organization has identified child obesity as one of the "most serious public health challenges of the 21st century" [16].

Identifying risk factors is crucial to developing preventive measures. Social ecological models of child obesity contain individual and environmental factors [27] including neighbourhood. In addition to the neighbourhood's physical and social environments, its socioeconomic position (SEP) plays a role. Neighbourhood SEP influences the spatial and social environment (e.g. walkability, organised programmes, safety), which, in turn, affects the individual situation (e.g. health behaviour, utilisation, stress) and, as a result, child body weight [10, 13, 44].

Although pre-school years are formative for the development of health behaviours, only a few studies investigate the impact of neighbourhood SEP on child obesity in this age group. These studies show that children from disadvantaged neighbourhoods are more frequently obese [7-9, 12, 24, 37, 39]. However, the effect of the neighbourhood is attenuated after the individual SEP is taken into account $[8,12-14,37$, 43]. Instead of continuing to investigate if neighbourhood deprivation influences child obesity, attention should be turned to focus on the conditions under which this is relevant $[22,26]$ and whether a high individual SEP might be protective in high deprived neighbourhoods. From a salutogenic perspective, it could be argued that a higher SEP with more psychosocial and financial resources for health promoting behaviour mitigates the damaging effect of neighbourhood deprivation. Methodically, this leads to the question whether individual socioeconomic characteristics moderate the influence of the neighbourhood on child health and development [24]. The only study known to us that takes up this issue shows that higher individual-level income was protective for children living in low deprived neighbourhoods, but not for children who lived in high deprived areas [33].

A further limitation is that only a small number of studies used large-scale representative samples. They analysed the influence of neighbourhood on child obesity in the context of school enrollment medical screenings [8, 9, 12, 37]. These offer the advantages of large samples and the participation of families from all social positions resulting in little selection bias [42]. However, the interaction of neighbourhood and individual SEP was not addressed in these studies.

Seizing upon these limitations, this study aims to investigate in a large and representative sample whether the relationship between neighbourhood deprivation and child obesity differs according to the child's individual SEP. Our hypothesis is that high individual SEP mitigates the effect of neighbourhood deprivation on child obesity. Understanding this association is important for effective policy initiatives to reduce child obesity disparities [13].

\section{Methods}

Our cross-sectional study is based on the school enrollment medical screening of the pre-school children cohorts (5-7 years) 2017 and 2018 in Duesseldorf, Germany. This examination was conducted by the municipal health authorities and supplemented by us with a standardised paper-and-pencil parental questionnaire [42]. A proband identification number was assigned to every participant linking data of the medical screening, the parental survey (e.g. education, income and occupation) and the social area code. A response rate of $66 \%$ allowed the inclusion of 6480 cases in the study. We excluded 824 cases with missing values for the analysed variables, so that 5656 children remained in the sample (52\% male). The excluded group has a higher prevalence of obesity $\left(\chi^{2}=19.98 ; p>.001\right)$, has a higher proportion of low and medium educated parents $\left(\chi^{2}=350.72 ; p>.001\right)$ and lives more often in deprived neighbourhoods $\left(\chi^{2}=150.70 ; p>.001\right)$ as compared to the included group. The method was approved by the ethics committee and complied with the principles of the Declaration of Helsinki (Study no. 5664).

Obesity was identified based on the age- and genderspecific body mass index (BMI). It was calculated using child's height, weight, sex and age which were objectively measured by the municipal health authorities. According to the gender- and age-specific percentiles of child BMI according to Kromeyer-Hauschild et al. [15], a child in the 90th percentile or above was classified as overweight and a child in the 97th percentile or above as obese. Overweight and obesity were combined into one category in the analyses and compared to the other children.

Neighbourhood deprivation was defined using the sociospatial degree of deprivation for children's residential addresses. The classification of the deprivation degrees was accomplished by the local authorities. Indicators like "welfare benefits", "unemployment" and "living space per person" classify 166 social spaces into five neighbourhood types ranging from "very low" to "very high" [18]. The sample size for the category "very high" $(n=306)$ was deemed too small for the analysis, so the categories "high" and "very high" were combined $(n=1,401)$; this resulted in four categories with "very low degree of deprivation" as reference category.

The individual SEP was measured using the level of parental education. Following the CASMIN ("Comparative Analysis of Social Mobility in Industrial Nations") 
classification [19], the highest general education diploma was combined with the highest level of vocational training for each parent. For parents with different levels of education, the higher level was selected. We wanted to compare the effect of neighbourhood deprivation on child obesity by individual SEP. Therefore, we used parental education as a binary variable to compare families with medium and low levels of education (at most the qualification to study at a university of applied science/university-track secondary school diploma with vocational training, CASMIN classification for the German educational system: 1a-2c_voc) with those who had a higher level of education (graduation from a university of applied science or a university, 3a-b).

Relevant covariates [17] are as follows: Parents' employment: if both parents were not working at the time of the survey, they were considered unemployed. The reference category was families in which at least one parent worked fulltime or part-time. Family status: if the child lived with only one parent, that parent was classified as a single parent family. Families in which both parents lived together served as reference category. Migration background: both parents were asked about their place of birth. If at least one parent had not been born in Germany, then a migration background was assumed. Families in which both parents had been born in Germany served as reference category.

\section{Data analysis}

The absolute and relative frequencies of child obesity were described according to neighbourhood deprivation for the entire sample and stratified according to parental education (Fig. 1). Chi-square tests were used to compare categorical variables between girls and boys or medium/low and high parental education. Multicollinearity analysis of all variables showed acceptable values of the variance inflation factors (VIFs) ranging from 1.0 to 1.2 (results not shown). Then, we used Poisson regression with robust standard errors to estimate adjusted prevalence ratios (PR) of child obesity by neighbourhood deprivation and parental education. We calculated PRs instead of odds ratios because they provide less biased estimates [3]. Model 1 shows the crude model. We adjusted for age, gender, parental employment status, family status and migration background (model 2). To analyse if the association between neighbourhood deprivation and obesity differs by parental education, we tested for interactions and included interaction terms (model 3). To compare both models without and with interactions, we used a Wald test to assess if the interactions significantly increased the model fit. All analyses were conducted using Stata 14.

\section{Results}

Table 1 shows the sample characteristics. 9.7\% of the children were overweight or obese. There were no differences between boys and girls $\left(\chi^{2}=0.06 ; p=.805\right)$. Twenty-eight percent and $25 \%$ of the children lived in neighbourhoods with medium and high deprivation, respectively. A total of $44 \%$ of the children lived in households with medium to low parental education.

Overall, the percentage of obese children increases with the degree of deprivation from 4.9 to $16 \%(p<.001)$. Figure 1 shows the percentage of obese children according to neighbourhood deprivation and parental education. The differences in the prevalences between very low and high deprived neighbourhoods were higher for children with higher educated parents $(2.8 \%$ vs. $12 \% ; p<.001)$ than for children with medium or low educated parents (13\% vs. $18 \%$; $p=.002$ ). Furthermore, children from families with high education were less often obese than children from lower educated families $(p<.001)$. This was observed in each stratum of
Fig. 1 Prevalences of child obesity by neighbourhood deprivation and parental education in percentages $(\%)$. Asterisks represent statistical significance $(* p<.05 ; * * p<.01$; $* * * p<.001)$

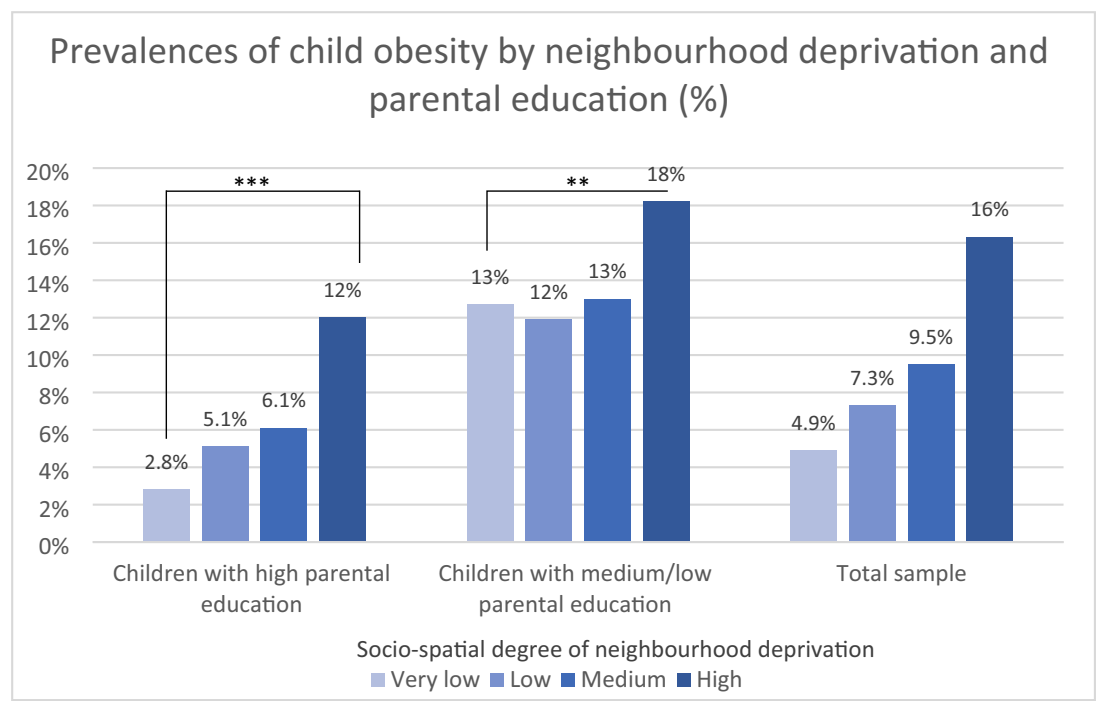


Table 1 Sample description: observations $(n)$ and percentages $(\%)$ or mean and standard deviation $(\mathrm{SD})$

\begin{tabular}{|c|c|c|c|}
\hline Sample characteristic ${ }^{1}$ & Categories & $\mathrm{n}$ & $\%$ \\
\hline \multirow[t]{2}{*}{ Gender } & Male & 2918 & 51.6 \\
\hline & Female & 2738 & 48.4 \\
\hline Age, years [mean (SD)] & & 5.95 & $(0.27)$ \\
\hline \multirow[t]{2}{*}{ Obesity } & No & 5106 & 90.3 \\
\hline & Yes & 550 & 9.7 \\
\hline \multirow[t]{4}{*}{ Neighbourhood deprivation } & Very low & 995 & 17.6 \\
\hline & Low & 1652 & 29.2 \\
\hline & Medium & 1608 & 28.4 \\
\hline & High & 1401 & 24.8 \\
\hline \multirow[t]{2}{*}{ Parental education } & High & 3148 & 55.7 \\
\hline & Medium/low & 2508 & 44.3 \\
\hline \multirow[t]{2}{*}{ Employment status } & At least one parent in employment & 5303 & 93.8 \\
\hline & Both parents are not employed & 353 & 6.2 \\
\hline \multirow[t]{2}{*}{ Family status } & Dual-parent families & 4,953 & 87.6 \\
\hline & Single parents & 703 & 12.4 \\
\hline \multirow[t]{2}{*}{ Migration background } & No & 2946 & 52.1 \\
\hline & Yes & 2710 & 47.9 \\
\hline Total & & 5656 & 100.00 \\
\hline
\end{tabular}

${ }^{1}$ Variable distributions are reported as $\mathrm{n}$ and $\%$ unless otherwise specified neighbourhood deprivation; however, the gap between these numbers closes with increasing neighbourhood deprivation: The differences between both educational groups range from $10.2 \%$ in the least deprived neighbourhood $\left(\chi^{2}=0.87\right.$; $p=.349)$ and $6.9 \%$ in the low $\left(\chi^{2}=12.38 ; p>.001\right)$ and medium deprived neighbourhoods $\left(\chi^{2}=16.49 ; p>.001\right)$ to $6 \%$ in the most deprived neighbourhood $\left(\chi^{2}=3.04 ; p=.081\right)$.

The adjusted PRs from the Poisson regression in Table 2 (model 2) confirm the results described above: The more deprived a neighbourhood is, the higher the prevalence of obese children. Compared with the reference group in a low deprived neighbourhood, the probability of obesity was twice as high in a highly deprived neighbourhood ( $\mathrm{PR}=2.02 ; \mathrm{CI}=$ 1.46-2.78). Likewise, parental education had an influence on obesity: Children from families with medium and low education have a probability for obesity that is twice as high compared to children from families with high education $(\mathrm{PR}=$ 2.05; CI $=1.46-2.78$ ). It should be noted that the PRs are

Table 2 Prevalence ratios with 95\% confidence intervals for child obesity; results of Poisson regression models $(n=5656)$

\begin{tabular}{|c|c|c|c|c|c|c|c|c|c|}
\hline & \multicolumn{3}{|c|}{ Model 1} & \multicolumn{3}{|c|}{ Model 2} & \multicolumn{3}{|c|}{ Model 3} \\
\hline & PR & CI $(95 \%)$ & $\mathrm{p}$ & $\mathrm{PR}$ & CI $(95 \%)$ & $\mathrm{p}$ & PR & CI $(95 \%)$ & $p$ \\
\hline Very low neighbourhood deprivation & \multicolumn{3}{|c|}{ Reference } & \multicolumn{3}{|c|}{ Reference } & \multicolumn{3}{|c|}{ Reference } \\
\hline Low neighbourhood deprivation & 1.34 & $0.97-1.85$ & .074 & 1.32 & $0.96-1.83$ & .087 & $1.77 \alpha$ & $1.09-2.86$ & .021 \\
\hline Medium neighbourhood deprivation & 1.54 & $1.12-2.12$ & .008 & 1.41 & $1.02-1.94$ & .036 & $2.00 \alpha$ & $1.22-3.26$ & .006 \\
\hline High neighbourhood deprivation & 2.29 & $1.66-3.15$ & $<.001$ & 2.02 & $1.46-2.78$ & $<.001$ & $3.59 \alpha$ & $2.20-5.87$ & $<.001$ \\
\hline High parental education & \multicolumn{3}{|c|}{ Reference } & \multicolumn{3}{|c|}{ Reference } & \multicolumn{3}{|c|}{ Reference } \\
\hline Medium/low parental education & 2.13 & $1.77-2.58$ & $<.001$ & 2.05 & $1.69-2.47$ & $<.001$ & $4.21 \beta$ & $2.44-7.24$ & $<.001$ \\
\hline Low deprivation $\mathrm{x}$ medium/low parental education & & & & & & & 0.53 & $0.28-1.01$ & .053 \\
\hline Medium deprivation $\mathrm{x}$ medium/low parental education & & & & & & & 0.48 & $0.25-0.89$ & .021 \\
\hline High deprivation $\mathrm{x}$ medium/low parental education & & & & & & & 0.36 & $0.20-0.67$ & .001 \\
\hline Pseudo $R^{2}$ & \multicolumn{3}{|c|}{0.043} & \multicolumn{3}{|c|}{0.053} & \multicolumn{3}{|c|}{0.056} \\
\hline
\end{tabular}

$P R$ prevalence ratio, $C I$ confidence interval, $p$ p-value, Pseudo $R^{2}$ McFadden's pseudo-R squared value. Model 1 unadjusted. Model 2 adjusted for age, child gender, employment status, family status and migration background. Model 3 adds interaction terms. $\alpha$ Main effects refer to the "high parental education" group only. $\beta$ Main effects refer to the "very low neighbourhood deprivation" group only. Wald test for interaction: $\chi^{2}=112.62, p<.001$ ) 
not directly comparable across the models because they were calculated on different baselines [41]. The main effects from model 1 and 2 show the relationship of child obesity for parental education and neighbourhood deprivation, respectively, without taking the other independent variable into account, whereas the main effects in the first block of model 3 refer to the "high parental education" group only. In this group, high neighbourhood deprivation increases the probability of child obesity by $3.59(\mathrm{CI}=2.20-5.87)$. The main effects in the second block in model 3 refer to the "very low neighbourhood deprivation" group only. In this group, medium/low parental education increases the probability of child obesity by 4.21 $(\mathrm{CI}=2.44-7.24)$. The interaction terms (neighbourhood deprivation $\mathrm{x}$ parental education) in block 3 in model 3 show that parental education significantly moderates the association between child obesity and neighbourhood deprivation. A Wald test confirms the significance $\left(\chi^{2}=112.62, p<.001\right)$.

The results are further illustrated in Fig. 2 based on the calculation of predicted prevalences in the adjusted model 3 with interaction terms. It can be seen that the predicted prevalences increase less sharply with neighbourhood deprivation in the group of children with medium/low parental education (very low: $13 \%$ vs. high: 17\%) than in the group of children with high parental education ( $3.0 \%$ vs. $11 \%)$. The association between neighbourhood deprivation and child obesity was stronger for higher parental education than for medium and low parental education. For children with high parental education, the prevalence remains low in low deprived neighbourhoods but increases with the degree of neighbourhood deprivation, whereas children with medium and low parental education have a higher prevalence rate throughout all neighbourhoods. However, the difference between both education levels becomes small in highly deprived neighbourhoods.

\section{Discussion}

It was observed that the percentage of obese children increases with neighbourhood deprivation. However, this increase is stronger for children with higher parental education than for those with medium or low parental education and to such a degree that the difference between education levels in highly deprived neighbourhoods becomes small. Moreover, in all neighbourhoods, children of lower educated parents are more frequently obese than children of higher educated parents. It was also seen that there was a stronger effect of neighbourhood deprivation for children with high parental education than for children with medium or low parental education.

The relationship between neighbourhood deprivation and child obesity confirms previous evidence $[14,20,36]$. The association revealed between parental education and child obesity is also comparable to the previous study results [20, $27,36]$. In the study by Igel et al. [12], however, education (here: maternal education) had no significant influence on the prevalence of obesity.

There is currently little evidence regarding the question whether the association between neighbourhood deprivation and child obesity differs according to individual SEP. The only study known to us by Rossen [33] makes the same finding that the relationship between neighbourhood deprivation and obesity in children with higher parental income is stronger than in children with lower parental income. The finding is thus stable across two different SEP indicators and samples; despite this, it is counterintuitive. From a salutogenic perspective, we argued that education mitigates the damaging effect of neighbourhood deprivation. Therefore we hypothesised a flatter gradient along neighbourhood deprivation for the highly educated group, but it is, by contrast, steeper. This could be
Fig. 2 Predicted prevalences (\%) of child obesity by neighbourhood deprivation and parental education based on margins calculated in Poisson regression with $95 \%$ confidence intervals. Predicted prevalences are adjusted for age, gender, employment status, family status and migration background

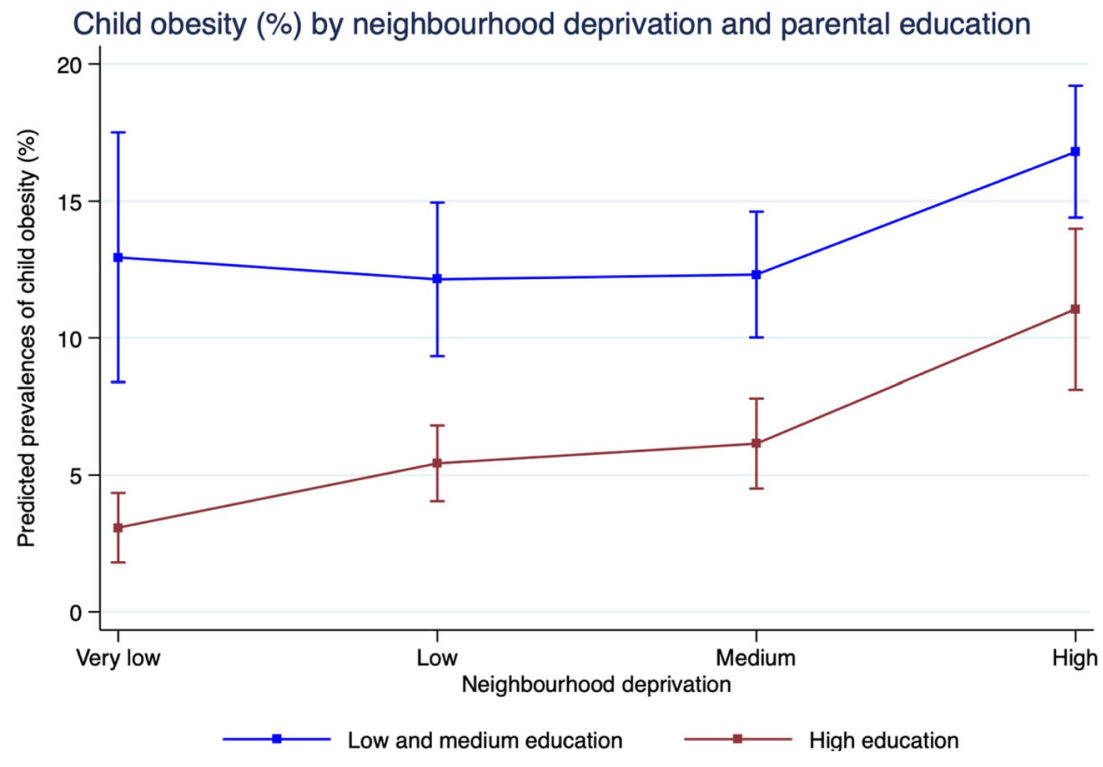


explained by the low prevalence of obesity in children of parents with a high education in a good neighbourhood. In other words, the baseline value is especially low. Conversely, the children whose parents have a medium and low education are more frequently obese even in good neighbourhoods. This speaks for the relevance of parental education regarding child obesity, independent of the environment.

Nevertheless, for both groups, the environment is relevant for child obesity. It is possible to distinguish between two mechanisms: (i) causation and (ii) selection. (i) On one hand, it can be assumed that neighbourhood deprivation favours an obesogenic environment [35]. For instance, high traffic density, a lack of parks and playgrounds and an inadequate infrastructure for local sports clubs limit the options for physical activity. Obesogenic environments are particularly relevant for children since they are restricted in their mobility and constantly embedded in their environment [35]. (ii) On the other hand, selection mechanisms could also be taking place. In this study, the high percentage of obese children of parents with high education in deprived neighbourhoods is striking. This could be due to downward social mobility, where highly educated parents move into socioeconomically disadvantaged neighbourhoods, e.g. as the result of separation or divorce. In a review [23], long maternal working hours and a permissive parenting style in high SEP families were risk factors for child obesity - factors that could occur more frequently in single parent households.

However, scrutinising the group of parents with high education in deprived neighbourhoods in our sample, it was observed that this frequently involved families with migration backgrounds (86\%). A study by Renzaho et al. [32] shows that this group has a lower level of obesity literacy and is subject to cultural influences affecting body image and eating habits that increase the risk of child obesity. Simultaneously, there are barriers to participation in prevention initiatives. This effect seems to exist also in parents with a migration background and a high level of education.

\section{Strengths and limitations}

This is one of the few studies on obesity focussing on the transitional phase from kindergarten to primary school and to investigate the importance of neighbourhood deprivation on the basis of a large sample with low selection bias [42]. One advantage is that we were able to draw upon medically determined body weights. In contrast, a number of studies used subjective information which raises the problem of incorrect memories or social desirability. A disadvantage is, however, that we have measured the individual SEP only on the basis of parental education. This produces missing values and the prevalence of children with obesity, living in deprived neighbourhoods and with low and medium educated parents is underestimated. Sensitivity analyses were conducted to test the robustness of findings with individual income as another indicator of individual SEP. Due to missing values on income $(15 \%)$ and household size (32\%), the calculation of the net equivalent income was only possible using a much smaller sample (4318 children). Analogous to the study by Rossen [33], the relationship between neighbourhood deprivation and child obesity was stronger for higher parental income compared to lower parental income; however, the interaction terms were not significant. This could be due to the small sample of obese children ( $n=393)$, resulting in small numbers for the categories. Finally, with the existing data, neighbourhood environment is measured by socioeconomic aspects, only. As we have pointed out at the beginning, these influence the spatial environment such as walkability and green spaces. Based on linkage with community geo data, this should be subject to further research.

\section{Conclusions}

In regard to child obesity prevention, there is a need to take action in deprived neighbourhoods. Through small-scale analysis of social structures particularly deprived urban neighbourhoods can be identified. The precise mechanisms through which the neighbourhood influences childhood development have not been clarified [38] nor have sufficient evidence been provided on the effectiveness of interventions [4]. Nonetheless, there are many recommendations on policies and environmental interventions [5, 11, 29, 41] including school environments [28].

Second, action is needed regarding children of parents with low education. Health literacy could be a field for intervention here, as it is less in low education groups [40]. Parental health literacy is associated with attitudes towards weight control for children [21] and child obesity [6, 25]. Consequently, strategies for weight loss in children should aim towards strengthening the health literacy of parents and supporting them in accessing evidence-based information [6, 21]. However, such approaches should be culturally sensitive [32].

Abbreviations BMI, Body mass index; CASMIN, Comparative analysis of social mobility in industrial nations; CI, Confidence interval; PR, Prevalence ratio; SD, Standard deviation; SEP, Socioeconomic position; VIF, Variance inflation factor

Author's contributions All authors contributed to the study conception and design. Material preparation and data collection were performed by Stefanie Lisak-Wahl and Katharina Kreffter; data analysis was performed by Thuy Ha Nguyen and Simon Götz. The first draft of the manuscript was written by Thuy Ha Nguyen and Simone Weyers, and all authors commented on the previous versions of the manuscript. All authors read and approved the final manuscript. 
Funding Open Access funding enabled and organized by Projekt DEAL. This work was supported by Federal Ministry of Education and Research (grant number 01EL1426C).

Data availability Data and material are not available for third parties.

Code availability All analyses were conducted using Stata 14 .

\section{Declarations}

Ethics approval The study was approved by the ethics committee of the Duesseldorf University Hospital (study nr. 5664).

Consent to participate All study participants gave informed consent to participation.

Consent for publication All study participants gave informed consent to scientific analysis and publication of study data.

Competing interests The authors declare no competing interest.

Open Access This article is licensed under a Creative Commons Attribution 4.0 International License, which permits use, sharing, adaptation, distribution and reproduction in any medium or format, as long as you give appropriate credit to the original author(s) and the source, provide a link to the Creative Commons licence, and indicate if changes were made. The images or other third party material in this article are included in the article's Creative Commons licence, unless indicated otherwise in a credit line to the material. If material is not included in the article's Creative Commons licence and your intended use is not permitted by statutory regulation or exceeds the permitted use, you will need to obtain permission directly from the copyright holder. To view a copy of this licence, visit http://creativecommons.org/licenses/by/4.0/.

\section{References}

1. Abarca-Gómez L, Abdeen ZA, Hamid ZA et al (2017) Worldwide trends in body-mass index, underweight, overweight, and obesity from 1975 to 2016. A pooled analysis of 2416 population-based measurement studies in 128.9 million children, adolescents, and adults. Lancet 390(10113):2627-2642. https://doi.org/10.1016/ S0140-6736(17)32129-3

2. Ahrens W, Pigeot I, Pohlabeln H, de Henauw S, Lissner L, Molnár D, Moreno LA, Tornaritis M, Veidebaum T, Siani A (2014) Prevalence of overweight and obesity in European children below the age of 10. Int J Obes (2005) 38(Suppl 2):S99-S107. https://doi. org/10.1038/ijo.2014.140

3. Barros AJD, Hirakata VN (2003) Alternatives for logistic regression in cross-sectional studies: an empirical comparison of models that directly estimate the prevalence ratio. BMC Med Res Methodol 3:21. https://doi.org/10.1186/1471-2288-3-21

4. Brennan LK, Brownson RC, Orleans CT (2014) Childhood obesity policy research and practice: evidence for policy and environmental strategies. Am J Prev Med 46(1):e1-e16. https://doi.org/10.1016/j. amepre.2013.08.022

5. Brown CL, Halvorson EE, Cohen GM, Lazorick S, Skelton JA (2015) Addressing childhood obesity: opportunities for prevention. Pediatr Clin N Am 62(5):1241-1261. https://doi.org/10.1016/j.pcl. 2015.05.013
6. Chari R, Warsh J, Ketterer T, Hossain J, Sharif I (2014) Association between health literacy and child and adolescent obesity. Patient Educ Couns 94(1):61-66. https://doi.org/10.1016/j.pec.2013.09. 006

7. Danielzik S, Czerwinski-Mast M, Langnäse K, Dilba B, Müller MJ (2004) Parental overweight, socioeconomic status and high birth weight are the major determinants of overweight and obesity in 57 y-old children: baseline data of the Kiel Obesity Prevention Study (KOPS). Int J Obes Relat Metab Disord 11:1494-1502. https://doi. org/10.1038/sj.ijo.0802756

8. Exeter DJ, Shackleton N, Browne M, Zhao J, Lee A, Crengle S (2019) Different domains of deprivation and their relationship with obesity in New Zealand 4-year-old children. Pediatr Obes 14(8): e12520. https://doi.org/10.1111/ijpo.12520

9. Gibb S, Shackleton N, Audas R, Taylor B, Swinburn B, Zhu T, Taylor R, Derraik JGB, Cutfield W, Milne B (2019) Child obesity prevalence across communities in New Zealand: 2010-2016. Aust N Z J Public Health 43(2):176-181. https://doi.org/10.1111/17536405.12881

10. Greves Grow HM, Cook AJ, Arterburn DE, Saelens BE, Drewnowski A (1982) Lozano P (2010) Child obesity associated with social disadvantage of children's neighborhoods. Soc Sci Med 71(3):584-591. https://doi.org/10.1016/j.socscimed.2010.04.018

11. Hodges EA, Smith C, Tidwell S, Berry D (2013) Promoting physical activity in preschoolers to prevent obesity: a review of the literature. J Pediatr Nurs 28(1):3-19. https://doi.org/10.1016/j. pedn.2012.01.002

12. Igel U et al (2013) Deprivation of the urban district and overweight in pre-schoolers. Adipositas 07(01):27-31. https://doi.org/10.1055/ s-0037-1618803

13. Kim Y, Cubbin C, Oh S (2019) A systematic review of neighbourhood economic context on child obesity and obesityrelated behaviours. Obes Rev 20(3):420-431. https://doi.org/10. 1111/obr. 12792

14. Kranjac AW, Denney JT, Kimbro RT, Moffett BS, Lopez KN (2019) Child obesity and the interaction of family and neighborhood socioeconomic context. Popul Res Policy Rev 38(3):347369. https://doi.org/10.1007/s11113-018-9504-2

15. Kromeyer-Hauschild K, Wabitsch M, Kunze D, Geller F, Geiß HC, Hesse V, von Hippel A, Jaeger U, Johnsen D, Korte W, Menner K, Müller G, Müller JM, Niemann-Pilatus A, Remer T, Schaefer F, Wittchen H-U, Zabransky S, Zellner K, Ziegler A, Hebebrand J (2001) Perzentile für den body-mass-index für das Kindes- und Jugendalter unter Heranziehung verschiedener deutscher Stichproben. Monatsschr Kinderheilkd 149(8):807-818. https:// doi.org/10.1007/s001120170107

16. Kumar S, Kelly AS (2017) Review of childhood obesity. From epidemiology, etiology, and comorbidities to clinical assessment and treatment. Mayo Clin Proc 92(2):251-265. https://doi.org/10. 1016/j.mayocp.2016.09.017

17. Lampert T, Schenk L, Stolzenberg H (2002) Konzeptualisierung und Operationalisierung sozialer Ungleichheit im Kinder- und Jugendgesundheitssurvey. Das Gesundheitswesen 64(S01):48-52. https://doi.org/10.1055/s-2002-39005

18. Landeshauptstadt Düsseldorf (2017) Sozialräumliche Gliederung. Fortschreibung 2017. Available at: https:/www.duesseldorf.de/ fileadmin/Amt12/statistik/stadtforschung/download/ Sozialraeumliche_Gliederung_Fortschreibung_2017.pdf. Accessed 02-11-2021

19. Lechert Y, Schroedter J, Lüttinger P (2006) Die Umsetzung der Bildungsklassifikation CASMIN für die Volkszählung 1970, die Mikrozensus- Zusatzerhebung 1971 und die Mikrozensen 19762004. Methodenbericht 2006/12, Mannheim

20. Li X, Memarian E, Sundquist J, Zöller B, Sundquist K (2014) Neighbourhood deprivation, individual-level familial and sociodemographic factors and diagnosed childhood obesity: a 
nationwide multilevel study from Sweden. Obes Facts 7(4):253263. https://doi.org/10.1159/000365955

21. Liechty JM, Saltzman JA, Musaad SM (2015) Health literacy and parent attitudes about weight control for children. Appetite 91:200 208. https://doi.org/10.1016/j.appet.2015.04.010

22. Martin G, Janus M, Enns J, Brownell M, Forer B, Duku E, Muhajarine N, Raos R (2016) Examining the social determinants of children's developmental health: protocol for building a panCanadian population-based monitoring system for early childhood development. BMJ Open 6(4):e012020. https://doi.org/10.1136/ bmjopen-2016-012020

23. Mech P, Hooley M, Skouteris H, Williams J (2016) Parent-related mechanisms underlying the social gradient of childhood overweight and obesity: a systematic review. Child Care Health Dev 42(5): 603-624. https://doi.org/10.1111/cch.12356

24. Minh A, Muhajarine N, Janus M, Brownell M, Guhn M (2017) A review of neighborhood effects and early child development: how, where, and for whom, do neighborhoods matter? Health Place 46: 155-174. https://doi.org/10.1016/j.healthplace.2017.04.012

25. Morrison AK, Glick A, Yin HS (2019) Health literacy: implications for child health. Pediatr Rev 40(6):263-277. https://doi.org/10. 1542/pir.2018-0027

26. Mountain J, Nyaradi A, Oddy W, Glauert R, de Klerk N, Straker L, Stanley F (2016) Data linkage in an established longitudinal cohort: the Western Australian Pregnancy Cohort (Raine) Study. Public Health Res Pract 26(3):10.17061/phrp2631636

27. Ohri-Vachaspati P, DeLia D, DeWeese RS, Crespo NC, Todd M, Yedidia MJ (2015) The relative contribution of layers of the social ecological model to childhood obesity. Public Health Nutr 18(11): 2055-2066. https://doi.org/10.1017/S1368980014002365

28. Paciência I, Cavaleiro Rufo J, Mendes F et al (2020) A crosssectional study of the impact of school neighbourhood on children obesity and body composition. Eur J Pediatr. https://doi.org/10. 1007/s00431-020-03798-y

29. Penney TL, Almiron-Roig E, Shearer C, McIsaac J-L, Kirk SFL (2014) Modifying the food environment for childhood obesity prevention: challenges and opportunities. Proc Nutr Soc 73(2):226236. https://doi.org/10.1017/S0029665113003819

30. Pont SJ, Puhl R, Cook SR, Slusser W (2017) Stigma experienced by children and adolescents with obesity. Pediatrics 140(6). https:// doi.org/10.1542/peds.2017-3034

31. Puhl R, Suh Y (2015) Health consequences of weight stigma. Implications for obesity prevention and treatment. Curr Obes Rep 4(2):182-190. https://doi.org/10.1007/s13679-015-0153-z

32. Renzaho AMN, Green J, Smith BJ et al (2018) Exploring factors influencing childhood obesity prevention among migrant communities in Victoria, Australia: A Qualitative Study. J Immigr Minor Health 20:865-883. https://doi.org/10.1007/s10903-017-0620-6

33. Rossen LM (2014) Neighbourhood economic deprivation explains racial/ethnic disparities in overweight and obesity among children and adolescents in the U.S.A. J Epidemiol Community Health 68(2):123-129. https://doi.org/10.1136/jech-2012-202245

34. Sahoo K, Sahoo B, Choudhury AK, Sofi NY, Kumar R, Bhadoria AS (2015) Childhood obesity. Causes and consequences. J Family Med Prim Care 4(2):187-192. https://doi.org/10.4103/2249-4863. 154628
35. Schneider S, Diehl K (2019) Adipogene Umwelten - was unsere Kinder dick macht. Public Health Forum 27(4):283-286. https:// doi.org/10.1515/pubhef-2019-0074

36. Schüle SA, Fromme H, Bolte G (2016) Built and socioeconomic neighbourhood environments and overweight in preschool aged children. A multilevel study to disentangle individual and contextual relationships. Environ Res 150:328-336. https://doi.org/10. 1016/j.envres.2016.06.024

37. Schüle SA, Kries R, Fromme H, Bolte G (2016) Neighbourhood socioeconomic context, individual socioeconomic position, and overweight in young children: a multilevel study in a large German city. BMC Obes 3:25. https://doi.org/10.1186/s40608016-0106-4

38. Sharkey P, Faber JW (2014) Where, when, why, and for whom do residential contexts matter? moving away from the dichotomous understanding of neighborhood effects. Annu Rev Sociol 40(1): 559-579. https://doi.org/10.1146/annurev-soc-071913-043350

39. Showell NN, Jennings JM, Johnson KA, Perin J, Thornton RLJ (2018) Where children live: examining whether neighborhood crime and poverty is associated with overweight and obesity among low-income preschool-aged primary care patients. Front Pediatr 6: 433. https://doi.org/10.3389/fped.2018.00433

40. Sørensen K, Pelikan JM, Röthlin F, Ganahl K, Slonska Z, Doyle G, Fullam J, Kondilis B, Agrafiotis D, Uiters E, Falcon M, Mensing M, Tchamov K, van den Broucke S, Brand H (2015) Health literacy in Europe: comparative results of the European health literacy survey (HLS-EU). Eur J Pub Health 25(6):1053-1058. https://doi.org/ 10.1093/eurpub/ckv043

41. Suglia SF, Shelton RC, Hsiao A, Wang YC, Rundle A, Link BG (2016) Why the neighborhood social environment is critical in obesity prevention. J Urban Health 93(1):206-212. https://doi.org/10. 1007/s11524-015-0017-6

42. Wahl S, Kreffter K, Frölich S, Müller-Thur K, Dragano N, Göbels K, Poschkamp T, Schäfer M, Weyers S (2018) Is the school entrance examination a door opener for health sciences research? Analyzing study participation of hard-to-reach groups. Bundesgesundheitsblatt 61(10):1236-1241. https://doi.org/10. 1007/s00103-018-2808-x

43. Ward ZJ, Long MW, Resch SC, Giles CM, Cradock AL, Gortmaker SL (2017) Simulation of growth trajectories of childhood obesity into adulthood. N Engl J Med 377(22):2145-2153. https://doi.org/10.1056/NEJMoa1703860

44. Wilde JA, Eilander M, Middelkoop BJC (2019) Effect of neighbourhood socioeconomic status on overweight and obesity in children 2-15 years of different ethnic groups. Eur J Pub Health. https://doi.org/10.1093/eurpub/cky277

45. Yang Y, Jiang Y, Xu Y, Mzayek F, Levy M (2018) A crosssectional study of the influence of neighborhood environment on childhood overweight and obesity: variation by age, gender, and environment characteristics. Prev Med 108:23-28. https://doi.org/ 10.1016/j.ypmed.2017.12.021

Publisher's note Springer Nature remains neutral with regard to jurisdictional claims in published maps and institutional affiliations. 